\title{
"Una via genuina a la verdadera filosofía". Estatuto y rol de la crítica filosófica en el Über das Wesen der philosophischen Kritik
}

\author{
"A path to genuine philosophy". Estatute and role of philosophi- \\ cal critique in Über das Wesen der philosophischen Kritik
}

Sandra Viviana Palermo

svsur@yahoo.it

(Università degli Studi di Pavia, Pavia, Itália)

Resumen: El presente trabajo concentra su atención sobre el estatuto y el rol de la crítica filosófica en la reflexión hegeliana de los primeros años de Jena, con la intención de poner en evidencia que el concepto de philosophische Kritik puede ser leído como una suerte de «punto de crisis» de la concepción hegeliana de la filosofía, así como la misma se había presentado en la Diferencia entre los sistemas de filosofía de Fichte y de Schelling: dentro de una concepción en virtud de la cual lo Absoluto está ya presente, el espacio lógico para el constituirse del pasaje entre error y verdad se diluye. De ahí que si la crítica filosófica debe configurarse como propedéutica a la verdadera filosofía, como elevación del no saber al saber, este último no podrá constituirse como totalidad acabada y completa ya presente, ni tampoco como tal que deje fuera de sí el saber inadecuado o finito; es decir no podrá constituirse como monísticamente compacto.

Palabras claves: crítica filosófica; filosofía; Absoluto; introductio in Philosophiam; saber finito-saber infinito
Abstract: The paper focuses the attention on the status and the role of philosophical critique in Hegel's early writings in Jena, with the aim of highlighting that the concept of philosophische Kritik can be read as a "point of crisis" of the conception of philosophy, that Hegel offer in his first publication, The Difference between Fichte's and Schelling's System of Philosophy: within a concept under which the Absolute is already present, the logical space of the passage between error and truth is dissolved. Hence, if the philosophical critique must be configured as propaedeutic to the true philosophy, as elevation from unkwowledge to knowledge, the latter can not be established as long as complete totality and as schon vorhanden, nor as such that it leave out of it the inadequate or finite konowledge.

Kewwords: philosophical critique; philosophy; introductio in Philosophiam; finite knowledge-infinite knowledge 
I.

En una carta del 30 de diciembre de 1801, Hegel comunica a Hufnagel su nuevo proyecto filosófico y el ánimo belicoso que lo infunde:

Hay algo nuevo en camino, el primer fascículo de un Periódico crítico de la filosofía, que voy a editar junto con Schelling [...] Este periódico se propone, por un lado, aumentar el número de las revistas <existentes> y, por el otro, poner un freno a la insensatez no-filosófica (den unphilosophischen Unwesen). Las armas de las que este periódico se servirá son numerosas, las llamaremos garrotes, látigos y férulas. Se hace todo esto por una buena razón y por la gloria dei; seguramente tendrán de qué lamentarse de un lado y del otro, pero cauterizar se ha vuelto realmente necesario'.

Estas anticipaciones a cerca del espíritu del Kritisches Journal der Philosophie, junto con la Ankündigung que anunciaba la publicación del primer número, y en la cual se decía que el objetivo de la revista era exponer «la esencia categórica de la filosofía en oposición al carácter negativo de la no-filosofía», constituyen un verdadero "manifiesto filosófico": un proyecto cultural y moral en sentido estricto, sobre el cual Hegel habría de ser más explícito en una de las Vorlesungen de los primeros años de Jena, indicando el objetivo del estudio filosófico como un «aprender a vivir a través de la filosofía» (durch Philosophie leben lernen)².

Tal proyecto pasaba antes que nada por la necesidad de distinguir la filosofía de la no filosofía, mas era inseparable de la exigencia de trazar «una via genuina» a la verdadera filosofía, de suerte que «de la mano de la crítica, el fundamento y el terreno de la verdadera filosofía podrán edificarse por sí mismos y crecer en paz» ${ }^{3}$. Desde este punto de vista, queda claro que la crítica filosófica no se presenta sólo como interpretación de posiciones filosóficas antecedentes o contemporáneas, sino que se constituye como una Wegbereitung, como preparación del camino o propedéutica a la filosofía. Lo que está en juego en la crítica filosófica no es un ejercicio puramente hermenéutico de «interpretación de libros»: la confrontación con las otras opciones filosóficas tiene como objetivo fundamental mostrar cómo el no saber ha de elevarse al saber, cómo se produce el pasaje a la Wissenschaft. La crítica filosófica es entonces enmendación; mas desde un concepto de Absoluto y de razón como «eternamente una y la misma cosa», la crítica no puede constituirse

\footnotetext{
1 HEGEL, G.W.F. Briefe, Bd. I, Hamburg: Meiner, 1965, p. 65 (trad. nuestra). Cfr., sobre este tema véase el volúmen de VIEWEG, K. (Hrsg.). Gegen das "unphilosophische Unwesen". Das Kritische Journal der Philosophie von Schelling und Hegel. Kritisches Jahrbuch der Philosophie, 7. Würzburg: Königshausen \& Neumann, 2002.

2 HEGEL, G.W.F. Gesammelte Werke, in Verbindung mit der Deutschen Forschungsgemeinschft, herausgegeben von der Nordrhein-Westfälichen Akademie der Wissenschaften und der Künste, Bd. IV. Hamburg: Meiner Verlag, 1968 ss., pp. 503-504. (de ahora en adelante cit. en el texto como GW, seguido por el volumen indicado en números romanos y la página indicada en números árabes).

3 GW, IV, 504.
} 
como mera actividad de corrección de doctrinas ajenas, cada una de ellas expresión de una razón diferente, sino que debe configurarse como ejercicio de enmendación que la razón ejerce consigo misma y sobre sí misma. El espacio propio de la crítica es así el espacio propio de una razón que debe encontrar el camino de la adecuación a sí misma.

Dentro de este contexto problemático, el presente trabajo concentra su atención sobre el estatuto y el rol de la crítica filosófica en la reflexión hegeliana de los primeros años de Jena, con la intención de poner en evidencia que el concepto de philosophische Kritik puede ser leído como una suerte de «punto de crisis» de la concepción hegeliana de la filosofía, así como la misma se había presentado en el texto que marcara el «debut filosófico» del autor, es decir la Diferencia entre los sistemas de filosofía de Fichte y de Schelling. En la medida en que Hegel aquí sostiene que el Absoluto «está ya presente, pues ¿cómo si no puede ser buscado?, es decir en la medida en que afirma que el Absoluto es Anfang y no Ziel de la filosofía - de suerte que no hay filosofía si no se parte de la «idea verdadera» de la razón, la cual es desplegarse en un «todo apoyado en sí mismo y completo en sí mismo» - el espacio de la crítica filosófica como vía de la adecuación del no saber al saber parece disolverse. Dentro de una concepción en virtud de la cual lo Absoluto está ya presente («ist schon vorhanden») ${ }^{5}$, el espacio lógico para el constituirse del pasaje entre error y verdad se diluye; y tampoco se entiende en qué medida algo así como un proceso de elevación del no saber al saber es necesario. De ahí que la concepción hegeliana de la crítica filosófica como propedéutica a la verdadera filosofía imponga la necesidad de repensar el concepto de filosofía como totalidad «completa en sí misma»${ }^{6}$, es decir, como monísticamente compacta. La verdad no podrá sólo configurarse como tal que está «ya presente» en concreto, ni tampoco como tal que deje fuera de sí el saber inadecuado o finito y por ende el pasaje del no saber al saber. En este sentido, se lee en Sobre la esencia de la crítica filosófica en general y su relación con el estado actual de la filosofía en particular ${ }^{7}$ : el no saber

4 HEGEL, G.W.F. Differenz des Fichte'schen und Schelling'schen Systems der Philosophie in Beziehung auf Reinhold's Beyträge zur leichtern Übersicht des Zustand der Philosophie zu Anfang des neunzehnten Jahrhunderts, 1 stes Heft, in Gesammelte Werke, Bd. IV (hrsg. von H. Buchner und O. Pöggeler). Hamburg: Meiner, 1968, p. 30 (de ahora en adelante cit. como DS., seguido por número árabe que indica la página); trad. esp. de Paredes Martín, M.C., Diferencias entre los sistemas de filosofía de Fichte y de Schelling. Madrid: Gredos, 2010, p. 33 (de ahora en adelante cit. como Dif., seguido por número áraba que indica la página).

5 DS., 15; Dif., 16. Sobre la tensión que se esconde en el concepto de «necesidad de la filosofía» cfr., PALERMO, S.V. Il bisogno della filosofia. L'itinerario speculativo di Hegel tra Francoforte e Jena (1797-1803). Milán: Mimesis, 2012, pp. 63-103.

6 DS, 12; Dif., 12.

7 El texto Über das Wesen der philosophischen Kritik überhaupt, und ihr Verhältnis zum gegenwärtigen Zustand der Philosophie insbesondere fue publicado en el $1^{\circ}$ cuaderno, del primer volumen del Kritisches Journal, en enero de 1802, pp. III-XXIV (ahora el texto se encuentra en GW, IV, 117-128). Del Kritisches Journal habrían de salir sólo dos volúmenes, cada uno de ellos con tres fascículos, 
«debe tener su esfera dentro de la filosofía». Comienza aquí entonces ese recorrido que llevará a Hegel a pensar el Absoluto no como Anfang, sino como Resultat, y la crítica filosófica no como camino propedéutico que se realiza por fuera del filosofía, sino como proceso completamente disuelto en ella, en tanto que esta última no es sino criticidad constitutiva.

Como es sabido, a cerca de la paternidad de los textos publicados en el Kritisches Journal ha habido muchas discusiones entre los intérpretes y el escrito sobre la Esencia de la filosofía es uno de aquellos sobre los que la Forschung parece todavía no encontrar un acuerdo definitivo ${ }^{8}$, si bien actualmente aún los intérpretes schellinghianos tienden a aceptar la atribución del texto a Hegel ${ }^{9}$. En este sentido, sin dejar de desconocer que el tono del escrito, así como también el uso de algunos términos, por parte de Hegel, son de clara matriz schellinghiana, creemos que la focalización del núcleo teórico que atraviesa el texto puede representar un elemento decisivo para la confirmación de que el mismo pertenece al recorrido teórico hegeliano. De hecho, a nuestro modo de ver, el texto sobre la Esencia de la crítica filosófica, constituye un momento fundamental del camino que lleva a Hegel a pensar el Absoluto no como primum de la filosofía sino como resultado de su propio proceso de constitución como tal ${ }^{10}$.

desde enero de 1802 hasta mayo de 1803, en que se publica el tercer fascículo del segundo volumen; cfr., sobre este tema, BUCHNER, H. Hegel und das Kritische Journal der Philosophie. Hegel-Studien, 3, 1965, pp. 95-156. Las traducciones del texto son nuestras; el mismo será cit. como WPK, seguido por número árabe correspondiente a la página.

8 Como se sabe, Hegel y Schelling no firmaban los artículos del Journal, de suerte que la determinación del autor de los mismos puede basarse sólo en lo que los mismos filósofos se han atribuido a posteriori o en el estudio del estilo, de la gramática y de la grafía de los escritos. En el caso del texto sobre la Esencia de la crítica, la discusión cuenta, por un lado, con un curriculum vitae redactado por Hegel y fechado 1804 - del cual nos da noticias Nohl en el prefacio a la edición de los Theologische Judendschriften (1907) (cfr., H. Nohl. Theologische Jugendschriften. Mohr, Tübingen 1907, pp. VIIIIX) - en el que Hegel se atribuye el texto introductivo al Kritisches Journal, y por el otro, con una carta de Schelling a Christine Weisse del 1838, en el que se dice que el filósofo no sólo se atribuye la dirección ideal del texto, sino además una participación expositiva concreta: «Respecto de la Introducción al Periódico crítico, la misma fue escrita parcialmente por Hegel, pero muchos pasajes que ahora no estaría en condiciones de indicar con precisión, así como las ideas principales (Hauptgedanken), me pertenecen; no hay siquiera un paso que yo no haya por lo menos revisado" (cit. en HEGEL, G.W.F. GW, IV, p. 542).

9 Cfr., TILLIETTE, X. Schelling. Une philosophie en devenir. Paris: Vrin, 1970, p. 126. Para una reconstrucción de la cuestión, cfr., GW, IV, pp. 540-543.

10 En general los intérpretes tienden a ver la participación schellinghiana sobre todo en la parte introductiva del texto, en la que aparecen algunos "motivos" propios de la reflexión de Schelling. Sin embargo, como intentaremos mostrar, aún dentro de este horizonte conceptual schellinghiano dominante, aún en la primera parte del texto se pone en evidencia las dificultades teóricas de una concepción monística del saber en la que el espacio lógico del pasaje del error a la verdad se disuelva. 
“Una via genuina a la verdadera filosofía”. Estatuto y rol de la crítica filosófica en el Über das Wesen der philosophischen Kritik

II.

En la Esencia de la crítica filosófica Hegel intenta delinear un concepto de crítica filosófica acorde a la nueva concepción de la filosofía, del Absoluto y de la razón que ha presentado en la Diferencia entre los sistemas de filosofía de Fichte y de Schelling ${ }^{11}$. Se trata para Hegel, como ha escrito Harris, de ofrecer una respuesta a la imagen del pensamiento especulativo ofrecida por Kant en la dialéctica trascendental y basada en la convicción de que el conflicto incesante entre las viejas escuelas dogmáticas es consecuencia de la intrínseca imposibilidad de la empresa en la cual tales escuelas se embarcan ${ }^{12}$. Lo que está en juego, concluye Harris, es la elaboración de una teoría de la crítica filosófica adecuada a la concepción de la «philosophia perennis».

Ahora bien, si es cierto que el objetivo del texto es el de configurar un concepto de philosophische Kritik adecuado a una concepción del Absoluto como Anfang, como tal que constituye el "lugar" desde el cual la filosofía adquiere forma y consistencia, es también cierto que en los primeros textos de Jena Hegel reconoce, junto a un Absoluto y una razón como ya disponibles, la «necesidad de la filosofía»; es decir, reconoce no sólo el ser ya efectivo y concreto del Absoluto, sino al mismo tiempo, el ser efectivo y concreto de la oposición, en virtud de la cual algo así como una necesidad de la filosofía puede venir a constiuirse: Hegel afirma que la unidad es efectiva y concreta, pues si no lo fuera, no sería posible siquiera el reconocimiento de la escisión como tal. Sólo desde y a partir de la unidad es posible reconocer los opuestos como opuestos, como tales que exigen la reconciliación ${ }^{13}$. Desde este punto de vista, la unidad no puede ser sino el Anfang de la filosofía, el punto desde el cual y a partir del cual se construye todo filosofar: el filosofar que no comienza a partir de la idea verdadera de la razón, escribe Hegel, no puede sino «dispersarse indefinidamente en finitudes absolutas ${ }^{14}$. Al mismo tiempo, el subsistir de algo así como una «necesidad de la filosofía» indica el «haber salido la conciencia del Absoluto», el no ser efectiva y concreta de la unidad, pues de otro modo no se sentiría ninguna exigencia de unificación. El hecho de que se de un Bedürfnis der Philosophie implica que de algún modo el punto de partida del filosofar no es el Absoluto, sino

11 Sobre la concepción hegeliana de la filosofía en los primeros años de Jena, cfr., CHIEREGHIN, F. Dialettica dell'assoluto e ontologia della soggettività in Hegel. Dall'ideale giovanile alla Fenomenologia dello spirito. Trento: Verifiche, 1980; DÜSING, K.. Das Problem der Subjektivität in Hegels Logik. Systematische und entwicklungsgeschichtliche Untersuchungen zum Prinzip des Idealismus und zur Dialektik, Hegel-Studien Beiheft, 15, Bouvier, Bonn 1995; KIMMERLE, H. Das Problem der Abgeschlossenheit des Denkens. Hegels "System der Philosophie" in den Jahren 18001804. Bonn: Bouvier-Grundmann, 1982.

12 HARRIS, H.S. Skepticism, Dogmatism and Speculation in the Critical Journal. En: Between Kant and Hegel. DI GIOVANNI, G. (ed.). New York: State University of New York Press, 1985, pp. 252-271.

13 Ya en Glauben und Sein Hegel escribía: «Lo que es contradictorio puede ser reconocido como tal sólo porque ha ya sido unificado»; Hegels theologische Jugendschriften, nach den Handschriften der Kgl. Bibliothek in Berlin, hrsg. von Dr. H. Noh. Tübingen: Mohr, 1907, p. 382 (trad. nuestra).

14 DS, 28; Dif., 31. 
la escisión; o cuanto menos, que si la unidad es, también la heterogeneidad y la separación son.

Esa «necesidad de la filosofía», que Hegel califica en el texto sobre la Diferencia como «presupuesto» de la misma ${ }^{15}$, "rompe" entonces la compacta identidad del Absoluto y por ende de la ciencia como sistema del saber acabado y completo en sí mismo: si la filosofía - como dice Hegel en la Differenzschrift - no es más que libre exposición de la razón, cuya autoproducción configura una «totalidad» apoyada en sí misma, que «no tiene fundamento alguno fuera de sí, sino que se fundamenta por sí mismo en su comienzo, en su medio y en su fin ${ }^{16}$, en ella no debería haber espacio lógico para la deficiencia o la incompletitud; como tampoco habría espacio para ningún movimiento de "elevación" al saber, de pasaje del no saber al saber: este último es, como tal, sólo en la medida en que «comienza consigo mismo» y no admite «ni predecesores ni sucesores» ${ }^{17}$. La «necesidad de la filosofía», en cambio, el «haber-salido» de la esfera de la ciencia y de lo absolutamente a priori, expresa el ser efectivo de una alteridad que la ciencia como tal no debería admitir.

La tensión entre estos dos polos, entre el estar presente y disponible del Absoluto y la «necesidad de la filosofía», que remite en cambio a un no ser efectivo y concreto del Absoluto, atraviesa todos los escritos hegelianos de los primeros años de Jena y aquí se condensan las problemáticas más importantes con las que el filósofo hace las cuentas; entre ellas, la cuestión de la introducción a la filosofía e, indisolublemente ligada a ésta, la cuestión de la crítica filosófica y de su relación con la filosofía. En todas estas cuestiones se pone en evidencia que el problema con el que Hegel se está midiendo es el de la relación entre el Absoluto - que no puede ser sino Anfang de la filosofía - y el proceso de acceso al Absoluto - el movimiento de "identificación", cuyo constituirse como tal presupone necesariamente el no ser primum del Absoluto y el ser efectivo y concreto de la escisión. Lo que intentamos decir es que lo que está en juego para el Hegel de los primeros escritos jenenses es la necesidad de dar cuenta del pasaje del endliches Erkennen al unendliches Erkennen, de la escisión a la identidad, dentro de una concepción de la razón y del Absoluto como identidad compacta y acabada en sí misma que sin embargo disuelve el espacio lógico de tal pasaje. De suerte que el mismo o se configura como tal que se realiza por fuera del Absoluto, y entonces no se comprende qué es lo que garantiza su carácter de genuino pasaje o se constituye como tal que se diluye dentro de la unidad del Absoluto, en cuyo caso vuelve a negarse como pasaje.

Dentro de una concepción del Absoluto como compacta identidad se vuelve arduo definir el estatuto lógico de un movimiento de acceso a esa identidad, de

15 DS, 15; Dif., 16-17.

16 DS, 30-31; Dif., 33.

17 DS,10; Dif., 11. 
una propedéutica al Absoluto. De ahí que cuando Hegel define la crítica filosófica como Introductio in Philosophiam, tal crítica no pueda eximirse de sufrir las mismas oscilaciones que sufre el concepto de introducción a la ciencia: por un lado, Hegel niega que la filosofía necesite vestíbulos; por el otro, no puede hacer a menos de reconocer la «necesidad de la filosofía», como exigencia de reunificación de los opuestos, de superación de la escisión. Pero ese proceso de reunificación, no pudiendo ser él mismo Absoluto - ya que éste se define como el «absoluto ser superado de la contraposición (absolute Aufgehobensein der Gegensätze)»-18, debe constituirse como ejercicio derivado y secundario. Al mismo tiempo, si el discurso propedéutico como movimiento de elevación de la oposición a la identidad, de pasaje del no saber al saber, se realiza por fuera del Absoluto, entonces, además de generarse el problema de una unidad que deja fuera de sí lo que no es unidad y por ende es unidad sólo parcial y limitada, se pone la cuestión de la legitimidad de tal movimiento como pasaje, pues en cuanto externo al Absoluto, ¿cómo ha de tenerse la certeza de que es realmente un proceso de elevación, que no ha de ser un movimiento destinado al fracaso? Si este movimiento no tiene él mismo carácter de «ciencia», entonces ¿qué es lo que garantiza que se constituya como verdadero movimiento de unificación, como genuino acceso o pasaje al Absoluto?

En el texto sobre la Esencia de la crítica filosófica la problemática que intentamos exponer se presenta explícitamente, declinándose como la cuestión de la relación de la verdadera filosofía con la no-filosofía, es decir como la cuestión de la relación del saber con el no saber. Las dificultades que el no saber pone a un saber que se pretende absolute evidencian que en la medida en que ese saber no logre dar cuenta del no saber y por ende del pasaje del no saber al saber, de la posibilidad de la elevación del error a la verdad, el saber mismo termina por desgarrarse y por mostrarse como algo limitado y por lo tanto no absoluto, es decir como un saber no verdadero. En el escrito en cuestión el concepto en el cual se condensan estas dificultades es, como intentaremos mostrar, el concepto de Verwerfung.

III.

La crítica filosófica, escribe Hegel, «exige un criterio (Maßstab) que sea independiente tanto de aquel que juzga como de lo que es juzgado, establecido no sobre la base del fenómeno (Erscheinung) singular, ni de la peculiaridad del sujeto sino a partir del modelo (Urbild) eterno e inmodificable de la cosa misma» ${ }^{19}$. Así como

18 Glauben und Wissen oder die Reflexionsphilosophie der Subjektivität, in der Vollständigkeit ihrer Formen, als Kantische, Jacobische und Fichtesche Philosophie. En: Gesammelte Werke, Bd. IV, hrsg. von H. Buchner und O. Pöggeler. Hamburg: Meiner, 1968, p. 325 (de ahora en adelante cit. como GuW, seguido por número árabe correspondiente a la página); trad. de V. Serrano, Fe y saber. Madrid: Biblioteca Nueva 2007, p. 66 (trad. modificada) (de ahora en adelante cit. como FyS, seguido por número árabe correspondiente a la página).

19 WPK, 117. 
la idea del arte bella no se define a partir de la crítica de arte, sino que constituye el punto de partida de esta última, la «verdadera idea» de la filosofía, escribe Hegel, es «presupuesto y condición» de la crítica filosófica. Es por ello que el filósofo puede decir que sólo allí adonde la idea está presente y disponible, la crítica filosófica tiene sentido. Si la crítica debe distinguir la auténtica filosofía de aquella que no lo es, no podría llevar a cabo tal operación si ella misma no se fundara en la idea de la filosofía.

Sin idea entonces no hay crítica. Pero sin idea, para Hegel, no hay tampoco filosofía. Desde este punto de vista, crítica y filosofía muestran una íntima solidaridad, pues ambas se basan sobre la verdadera idea de la razón ${ }^{20}$. Pero si por un lado la distinción entre crítica filosófica y filosofía tiende a disolverse, por el otro, tal distinción se mantiene, pues mientras la identidad entre filosofía e idea parece ser completa, ya que la filosofía es, a partir de la idea verdadera de la razón, desarrollo de conceptos que se configura «en una totalidad objetiva», la crítica - escribe Hegel- presupone la idea sólo como Urbild, o modelo objetivo a partir del cual medir los distintos sistemas filosóficos. En este caso, entre idea y crítica parece existir una alteridad que está ausente en el caso de la filosofía; pues en la filosofía la idea constituye el Anfang de un movimiento de autoproducción de la razón que lleva inscripto en sí mismo el desplegarse en una «totalidad orgánica». La crítica, en cambio, parece presentarse come externa y subordinada a la idea ${ }^{21}$. Esta ambivalencia de identidad y alteridad entre crítica filosófica y filosofía corresponde, a nuestro modo de ver, a la función que Hegel asigna a la crítica como introducción a la filosofía y al ambiguo estatuto que tal concepto adquiere dentro del cuadro conceptual hegeliano de los primeros años de Jena: justamente porque la identidad es primum y disuelve el espacio lógico del movimiento de identificación, allí adonde tal movimiento se presente, éste deberá oscilar necesariamente entre ser él mismo identidad - anulándose como movimiento de identificación - o constituirse como movimiento de identificación que, sin embargo, realizándose por fuera de la identidad, mantiene una alteridad que no está en condiciones de consumir. Alteridad que aquí se presenta como exterioridad de la crítica a la idea, la cual es Urbild, bajo el cual subsumir todo ejercicio filosófico.

Ahora bien, afirmar que no hay crítica sin idea significa para Hegel sostener no sólo que la crítica es posible sólo cuando la misma se funda sobre la idea verdadera de la razón, sino además que la crítica tiene sentido sólo cuando ella se dirige a obras en las cuales tal idea está presente:

20 Hegel define esta idea en una de las tesis que acompañaban la disertación, De orbitis planetarum, como «synthesis infiniti et finiti» y agrega que la «philosophia omnis est in ideis»; cfr. GW, V, 246.

21 Riccardo Pozzo reconoce aquí un esquema de derivación platónica, en virtud del cual el concepto de crítica se configura sobre la base de la relación esencia infinita (idea) y fenómenos transeuntes propios del mundo finito (sistemas filosóficos que se dan en la historia de la filosofía); POZZO, R. Hegel 'Introductio in Philosophiam'. Dagli studi ginnasiali alla prima logica (1782-1801). Firenze: La Nuova Italia, 1989, p. 208. 
La crítica como evaluación objetiva [objektive Beurteilung] es en general posible por el hecho de que la verdad de la razón, así como la belleza, es sólo una, y se sigue de aquí que ella [la crítica] tiene sentido sólo para aquellos en los que la idea de la única e idéntica filosofía está presente; al mismo tiempo la crítica sólo puede concernir a aquellas obras en las que esta idea se da a conocer de manera expresa más o menos claramente ${ }^{22}$.

Cuando la crítica se dirige a obras en las que la idea está ausente, en cambio, su tarea parece resultar imposible de llevar a cabo:

Respecto de aquellos y en aquellas obras que se viesen privadas de esa idea, la tarea de la crítica sería totalmente vana. Allí adonde falta tal idea la crítica se halla en la mayor dificultad (am meisten in Verlegenheit); pues si toda crítica no es más que subsunción bajo la idea, allí adonde la misma está ausente, toda crítica cesa necesariamente, y tal crítica no puede darse ninguna otra relación inmediata que la del rechazo (Verwerfung) ${ }^{23}$.

Si la crítica es subsunción bajo la idea, aquello que se "resiste" a la misma, aquello que no se deja subsumir bajo la idea, pues no presenta ninguna afinidad con ella, pone a la crítica en la mayor de las dificultades: la única reacción que a la crítica le queda es la del rechazo, la de la reprobación. Sin embargo, dice Hegel, con tal rechazo,

la crítica rompe completamente toda relación entre aquello a lo cual falta la idea de la filosofía y aquello al servicio del cual está ella. Dado que de esta manera el reconocimiento recíproco (gegenseitige Anerkennen) es superado (aufgehoben), aparecen sólo dos subjetividades enfrentadas. Cosas que no tienen nada en común se presentan justamente por eso con igual derecho, y la crítica, declarando que el objeto de su juicio - aunque pretenda ser sólo filosofía - es de todo salvo filosofía, y por ende una nulidad, se coloca en una posición subjetiva, y su declaración se presenta como una sentencia unilateral; posición, ésta, que - en la medida en que el operar de la crítica debe ser objetivo - contradice inmediatamente su esencia. ${ }^{24}$

Se trata, a nuestro modo de ver, del pasaje fundamental del texto; aquí la exigencia de la crítica filosófica, entendida como movimiento de enmendación o corrección capaz de constituirse como pasaje del no saber al saber, impone a la concepción monística del saber como tal que es absolute o no es, un "punto de inflexión" o de "crisis": la crítica filosófica como tal que se funda sobre la idea de la razón, sobre el saber verdadero, ante el no saber no puede sino comportarse negativamente; no puede sino rechazarlo, porque desde el Standpunkt del saber en

\footnotetext{
22 WPK, 118.

23 WPK, 118.

24 WPK, 118.
} 
cuanto saber absoluto no hay lugar para el no saber. Como tampoco entonces puede haber lugar para el pasaje del no saber al saber. El acto de intelligere es absoluto, o no es; de suerte que aquí el espacio lógico del error, de la duda o de la enmendación de los mismos queda completamente disuelto. Desde este punto de vista, es evidente que el rechazo constituye la única respuesta posible del saber hacia el no saber. Esa respuesta pone en evidencia la inadmisibilidad, desde el saber, del no saber; inadmisibilidad esencial al saber como tal. Mas tal rechazo representa, al mismo tiempo, la renuncia del saber a su propia absolutez, es decir, representa al mismo tiempo la renuncia del saber a sí mismo. En la medida en que la crítica rechaza el no saber reconociéndolo como tal, es decir en la medida en que la crítica afirma que el no saber no es nada para el saber, se muestra ella misma como no saber, como posición unilateral y subjetiva.

Hegel expresa esta situación afirmando que en la Verwerfung, la crítica rompe la relación con aquello al servicio de lo cual ella está, la filosofía, el saber como tal: afirmando que aquello que encuentra frente a sí es no saber, el saber admite que existe algo que queda fuera de él. Mas este gesto es la admisión del saber de que no es saber absoluto. El saber se desgarra, admite una fractura entre sí mismo y lo que no es saber; lo que queda por fuera de él. Mas este fuera destruye el saber como saber absoluto:

Su juicio [el de la crítica que opera desde la idea verdadera] es un apelarse a la idea de la filosofía, que sin embargo, no siendo reconocida por la parte contraria, es para esta última una corte de justicia ajena. Frente a esta relación de la crítica que, distinguiendo la no filosofía de la filosofía (Unphilosophie von der Philosophie abscheidet), está de un lado y tiene del lado opuesto la no filosofía, no hay en lo inmediato salvación posible. ${ }^{25}$

El saber no puede sino rechazar el no saber, declararlo como tal mostrándose al mismo tiempo como externo y ajeno a él. Esta declaración, sin embargo, comporta la renuncia del saber a sí mismo, «a su propia esencia». Si el error y la duda se declaran como cualitativamente distintos, opuestos al saber, y son puestos fuera de él, en tantos que externos niegan el saber como absolute: allí «no hay salvación posible». Ni para la crítica, ni para la filosofía. Allí adonde no hay «reconocimiento recíproco», el destino de la crítica - como la del saber y de la filosofía - es el de la finitud y la oposición; el mismo del Jesús de El espíritu del cristianismo y su destino, que justamente por su incapacidad de tomar sobre sí lo negativo del mundo, se ve obligado a declarar que el "reino de Dios" no es de este mundo, y a retirarse entonces de él, resignándose a llevar tal reino sólo en su propia «conciencia infeliz».

En la Esencia de la crítica filosófica Hegel accede entonces al reconocimiento de la exigencia de que saber y no saber se reconozcan «recíprocamente»:

25 WPK, 119; corsivo nuestro. 
no queda otra cosa por hacer que contar cómo ese lado negativo se expresa y confiesa su propio no ser, el cual en la medida en la que se manifiesta (eine Erscheinung hat) es banalidad (Plattheit). Y dado que es inevitable que lo que en el comienzo [Anfang] es nada en su ulterior proceder se muestre cada vez más como nada, de suerte que sea de manera casi universal reconocido como tal, la crítica, mediante esta construcción conducida a partir de la primera nulidad, concilia también esa incapacidad, que en la primera sentencia podía ver sólo capricho y arbitrio. ${ }^{26}$

El reconocimiento recíproco se presenta aquí como el proceso en el cual el no saber se reconoce a sí mismo como tal, es decir es entendido como un desarrollo en el que la «nada» que ese no saber es se revele a sí misma, y justamente por eso pueda constituirse como el lado negativo de una razón que requiere, para su «completamiento» un lado positivo. Es aquí adonde Hegel pone en evidencia que la crítica filosófica comparte su tarea con la lógica, que en los primeros años de Jena presentaba un carácter claramente introductivo y tenía como objetivo llevar las determinidades del entendimiento a precipitar en el «abismo» del Absoluto ${ }^{27}$. Más importante aún, a nuestro modo de ver, es que aquí Hegel explicite la conciencia de que el concepto de saber, como saber absolute, no puede constituirse como tal si no da cuenta, dentro de su propio espacio lógico, del no saber y junto con ello del pasaje del no saber al saber, del error a la verdad.

Desde este punto de vista, el texto sobre la Esencia de la crítica filosófica, aún en la primera parte, que la mayoría de los intérpretes reconoce como aquella en la cual la presencia de Schelling sería preponderante ${ }^{28}$, se revela como un escrito de clara matriz hegeliana, cuyo resultado comporta la necesidad de que «el lado subordinado y deficiente» de los distintos reflejos del espíritu encuentre «su esfera en la filosofía»29. La reflexión sobre el estatuto y el lugar lógico propio de la crítica como introducción a la filosofía, como camino propedéutico del saber finito e inadecuado al saber infinito y adecuado, lleva a Hegel a plantearse, de manera cada vez más explicita, la exigencia de un concepto de saber - y por ende de Absoluto - capaz de "comerciar" con el no saber, pues de otro modo el Absoluto mismo se mostraría como deficiente e incompleto.

El recorrido del escrito sobre la Esencia de la crítica filosófica concluye con la afirmación que cuando la crítica filosófica se dirige hacia obras en las que la

\section{WPK, 119.}

27 Sobre el rol de la lógica en los primeros años de Jena, cfr., DÜSING, K.. Das Problem der Subjektivität in Hegels Logik. Systematische und entwicklungsgeschichtliche Untersuchungen zum Prinzip des Idealismus und zur Dialektik, Hegel-Studien Beiheft, 15, Bouvier, Bonn 1995, pp. 75-208. Cfr., además, RUGGIU, L. Logica metafisica politica. Hegel a Jena, 2 voll. Milano: Mimesis, 2010, vol. 1 , pp. $70-120$.

$28 \mathrm{Cfr}$, por ejemplo, CASADEI, G. Idea di mediazione e immanenza critica nel primo Hegel. Pisa: ETS, 1995, p. 254.

29 WPK, 120. 
verdadera idea de la filosofía está presente su tarea es la de «mostrar claramente el modo y el grado en el que ella [la idea] emerge de manera libre y clara, así como también [mostrar] en qué medida ella se ha elaborado en una sistema científico de la filosofía» ${ }^{30}$. Si es cierto, como ha mostrado Giuseppe Casadei, que en esta afirmación Hegel comienza «a dar un giro epistemológico apreciable y rico de insospechables implicancias metódicas al motivo en sí demasiado especulativo [...] de la operación crítica como mera "subsunción bajo la idea" ${ }^{31}$, es también cierto que a la necesidad del carácter "mediativo" de la crítica - y por ende del saber - Hegel accede gracias a la reflexión sobre el destino de una crítica que, desde la idea verdadera de la razón, resulte incapaz de dar cuenta del no saber. En este sentido, la reflexión sobre la crítica filosófica constituye entonces un "punto de inflexión" en el recorrido filosófico hegeliano, en la medida en que el concepto de «rechazo» y sus implicancias teóricas conllevan la revisión de una idea de saber como monísticamente compacto; como tal que desde él y en él no hay lugar para el no saber, y por lo tanto para el pasaje del no saber al saber. Dicho de otro modo, la exigencia de dar cuenta del pasaje exigencia que se expresa en la necesidad de una introducción a la filosofía y que se declina en la tarea más propia de la crítica filosófica - comporta, para el filósofo, la necesidad de pensar un saber que no se constituya solamente como indiferencia en el sentido schellinghiano, como lugar en el que los opuestos precipitan, pues en ese caso el Absoluto se determinaría como "más allá" del proceso que a él debe acceder y por lo tanto como "otro" respecto de tal proceso, de suerte que, por un lado, esa "distinción" sería la heterogeneidad que ha de eliminarse, por el otro, el proceso de acceso no se constituiría como genuino acceso y el Absoluto, manteniendo algo por fuera de él, tampoco se constituiría como genuino Absoluto.

\section{IV.}

A través del recorrido realizado, intentamos mostrar cómo la reflexión hegeliana de los primeros años de Jena sobre el rol y el estatuto del concepto de crítica filosófica se impone como "punto de crisis" de un concepto de saber como absoluto y como monísticamente compacto. De hecho, la convicción hegeliana - de los primeros textos jenenses - de que el Absoluto es primum, condición «ya disponible» de todo filosofar, disuelve el espacio lógico de todo proceso de acceso al Absoluto: si la unidad está ya disponible, si la misma es concreta y efectiva, entonces no puede surgir ningún movimiento de unificación; puesto que tal movimiento implica necesariamente la no unidad. Lo mismo sucede si el punto de partida es el saber en cuanto absolute, pues desde tal saber no se entiende en qué medida algo así como un acceso al mismo pueda venir a constituirse. El saber en cuanto absoluto agota el espacio lógico de

30 WPK, 119.

31 CASADEI, G. Idea di mediazione e immanenza critica nel primo Hegel. Pisa: ETS, 1995, p. 265. 
todo proceso de elevación o de pasaje del no saber al saber; agota, entonces, el espacio lógico de una introducción al saber y por ende de la crítica entendida como Wegbereitung a la metafísica, que es la filosofía strictu sensu. Sin embargo, lo que a través del ensayo sobre la esencia de la crítica queda claro es que si el pasaje del no saber al saber es negado entonces el saber mismo termina por constituirse como no saber, como saber parcial e inadecuado. De ahí que sea esencial para el saber mismo - tanto como para el no saber - mostrar el modo en el cual el no saber se eleva «a partir de una fuerza propia» al saber.

Desde este punto de vista, se notan aquí, a nuestro modo de ver, los elementos fundamentales que habrán de llevar la reflexión hegeliana a un desplazamiento del cuadro teórico presente; desplazamiento del cual el método fenomenológico da cuenta, pues aquí la ciencia no se relaciona al no saber rechazándolo, ni tampoco lo hace presuponiéndose a sí misma en el no saber como tal que estaría presente pero de manera sólo ofuscada o implícita; en la Fenomenología del espíritu no hay otro punto de partida que el del saber que se ha de criticar: no hay dos partes que se miden, pues la unidad de medida y la materia a examinar se encuentran en la conciencia misma, que desde sí misma, en virtud de su intrínseco impulso por alcanzar la verdad, se pierde a sí misma, pero este perderse es al mismo tiempo su erigirse a ciencia ${ }^{32}$. En el Hegel maduro, entonces, la crítica filosófica no habrá de presuponer como su condición la idea como Urbild eterno e inmodificable al cual subsumir todo ejercicio filosófico, y su mismo operar. No habrá entonces distinción entre idea y crítica. Tanto como no habrá distinción entre crítica y filosofía. Pero la crítica podrá resolverse en la filosofía, en la medida en que esta última se constituya a su vez ella misma como crítica, como proceso de acceso a sí misma, que es al

32 En la Introducción a la Fenomenología del espíritu Hegel presenta tres modos de relación del saber con el no saber: el primero de ellos consiste en un rechazo (verwerfen) del saber no verdadero de parte del saber verdadero; aquí Hegel se refiere a esta modalidad de la misma manera en que lo ha hecho en el texto de los primeros años de Jena, dejando en claro, como allí, que en la medida en que el saber rechace el no saber como saber erróneo o infundado, intentando asegurarse a sí mismo a partir de ese rechazo, termina por volverse él mismo aserción subjetiva y parcial, tan infundada como aquella que está intentando excluir. La segunda modalidad de relación del saber al no saber consistiría en un presentir en el no saber el saber verdadero como tal que está presente pero en una forma ofuscada o borrosa, de suerte que el objetivo de la crítica, en ese caso, sería el de llevar tal saber a expresarse de manera explícita y clara. También en este caso la ciencia se apelaría a un ser, se supondría a sí misma como tal que está presente en el no saber, sólo que de manera equivocada; de suerte que no hay en esta modalidad ninguna inmanencia. El único método inmanente es el método fenomenológico, en el cual no hay ninguna unidad de medida por fuera del saber que se ha de criticar. Stephen Houlgate lee estas consideraciones hegelianas a cerca de la relación del saber con el no saber como una presentación de su enfoque más maduro a cerca de la cuestión de la «crítica filosófica»; HEGEL, G.W.F. Phänomenologie des Geistes. En: GW, IX (Hrsg. von W. Bonsiepen-R. Heede). Hamburg: Meiner, 1980; trad. esp. de Roces W. Fenomenología del espíritu. México D.F.: Fondo de Cultura Económica, 2009, pp. 53-54. Cfr. sobre este punto, HOULGATE, S. Glauben und Wissen: Hegels immanente Kritik der kantischen Philosophie oder die (illegitime) «Ahnung eines besseren»? En: Arndt A.-Bal K.-Ottmann H. Hegel Jahrbuch 2005: Glauben und Wissen (Dritter Teil). Berlin: Akademie Verlag 2005, pp. 152-158. 
mismo tiempo, el proceso en el cual se autoconstituye como tal. Si el Hegel del Über das Wesen der philosophischen Kritik puede escribir que la filosofía es sólo una pues la razón es sólo una y que «así como no pueden darse razones distintas, tampoco podría darse entre la razón y su autorreconocerse una pared, a través de la cual este autorreconocerse pudiese resultar una esencial diversidad del fenómeno»33, el Hegel post fenomenológico, aún ratificando la idea de que «la razón considerada de manera absoluta y la razón como objeto de sí misma en su autorreconocerse, es decir como filosofía, es de nuevo una y la misma cosa», habría seguramente recalcado que no hay una razón y una actividad de autorreconocerse de la misma que sean a su vez idénticas, sino que en el proceso de autorreconocerse, la razón se constituye como tal; y no hay razón por fuera de esta actividad.

\section{Referencias}

Para los textos de Hegel, utilizamos: HEGEL, G.W.F. Gesammelte Werke, in Verbindung mit der Hegel-Kommission der Rheinisch-Westfälischen Akademie der Wissenschaften und dem Hegel-Archiv der Ruhr-Universität Bochum (Düsseldorf). Hamburg: Meiner, 1968 ss.

BUCHNER, H. Hegel und das Kritische Journal der Philosophie. Hegel-Studien, 3, 1965.

CASADEI, G. Idea di mediazione e immanenza critica nel primo Hegel. Pisa: ETS, 1995.

CHIEREGHIN, F. Dialettica dell'assoluto e ontologia della soggettività in Hegel. Dall'ideale giovanile alla Fenomenologia dello spirito. Trento: Verifiche, 1980.

ÜSING, K. Das Problem der Subjektivität in Hegels Logik. Systematische und entwicklungsgeschichtliche Untersuchungen zum Prinzip des Idealismus und zur Dialektik, Hegel-Studien Beiheft, 15, Bouvier, Bonn 1995.

HARRIS, H.S. Skepticism, Dogmatism and Speculation in the Critical Journal, en Between Kant and Hegel. DI GIOVANNI, G. (ed.). New York: State University of New York Press, 1985

HOULGATE, S. Glauben und Wissen: Hegels immanente Kritik der kantischen Philosophie oder die (illegitime) «Ahnung eines besseren»? En: Arndt A.-Bal K.Ottmann H., Hegel Jahrbuch 2005: Glauben und Wissen (Dritter Teil). Berlin: Akademie Verlag 2005, pp. 152-158.

JONKERS, Philosophische Kritik in Hegels Systemkonzeption von 1801/02. En: KIMMERLE, H., Die Eigenbedeutung der Jenaer Systemkonzeptionen Hegels.

33 WPK, 118. 
“Una via genuina a la verdadera filosofía”. Estatuto y rol de la crítica filosófica en el Über das Wesen der philosophischen Kritik

Berlin: Akademie Verlag, 2004, pp. 45-60.

KIMMERLE, H. Das Problem der Abgeschlossenheit des Denkens. Hegels "System der Philosophie" in den Jahren 1800-1804. Bonn: Bouvier-Grundmann, 1982.

PALERMO, S.V. Il bisogno della filosofia. L'itinerario speculativo di Hegel tra Francoforte e Jena (1797-1803). Milán: Mimesis, 2012.

POZZO, R. Hegel 'Introductio in Philosophiam'. Dagli studi ginnasiali alla prima logica (1782-1801). Firenze: La Nuova Italia, 1989.

RUGGIU, L. Logica metafisica politica. Hegel a Jena, 2 voll. Milano: Mimesis, 2010.

TILLIETTE, X. Schelling. Une philosophie en devenir. Paris: Vrin, 1970.

VIEWEG, K. (Hrsg.) ,Gegen das "unphilosophische Unwesen”. Das Kritische Journal der Philosophie von Schelling und Hegel. Kritisches Jahrbuch der Philosophie, 7, Würzburg: Königshausen \& Neumann, 2002.

Recebido em: 18.11.2014

Aceito em: 06.03.2015 